Original Article

\title{
ASSESSMENT OF PATIENT COUNSELLING IN DIABETIC AND HYPERTENSIVE PATIENTS IN TERMS OF PATIENT KNOWLEDGE ABOUT THEIR MEDICATION, DISEASE STATE AND LIFESTYLE MODIFICATIONS BY PHARMACY PERSONNEL AT LDF CLINIC IN MASERU
}

\author{
LINEO MAJA1, THABISO MASIA ${ }^{2}$, KABELO BINYANE², MASEABATA RAMATHEBANE ${ }^{3}$
}

${ }^{1}$ Lecturer, Department of Pharmacy, National University of Lesotho, ${ }^{2}$ Student, Department of Pharmacy, National University of Lesotho, 3Senior Lecturer, Department of Pharmacy, National University of Lesotho

Email: majalineo@gmail.com

Received: 15 Dec 2017 Revised and Accepted: 13 Feb 2018

\begin{abstract}
Objective: To investigate if diabetic and hypertensive patients were being adequately counselled by pharmacy personnel about their medication, disease states and lifestyle modifications at Lesotho defence force (LDF) clinic in Maseru.

Methods: A cross-sectional study was conducted among diabetic and hypertensive patients treated at LDF clinic in Maseru from March to May 2017. A semi-structured questionnaire was used to collect data in a face-to-face interview with patients. Microsoft Excel 2010 was used to analyse collected data.

Results: The study population consisted of 222 participants; 22 (28.2\%) of diabetic. respondents had inadequate knowledge of diabetes mellitus complications and $56(71.8 \%)$ had no knowledge of complications. $153(78.8 \%)$ of hypertensive respondents had inadequate knowledge of hypertension complications and 33 (17.1\%) had no knowledge of complications. 56 (25.2\%) had adequate knowledge of lifestyle modifications of diabetes mellitus and hypertension and 164 (73.9\%) had inadequate knowledge. 182 (82.0\%) had adequate knowledge of their anti-hypertensive and anti-diabetic medicines names, 20 (9.0\%) had inadequate knowledge and $20(9.0 \%)$ had no knowledge. 63 (28.4\%) had adequate knowledge of their medicines strengths, 17 (7.7\%) had inadequate knowledge and 142 (64.0\%) had no knowledge. 199 (89.6\%) respondents had adequate knowledge of dosing frequency and $20(9.0 \%)$ had inadequate knowledge.
\end{abstract}

Conclusion: Hypertensive and diabetic patients' knowledge about medication, disease states and lifestyle modifications were inadequate due to poor patient counselling on such aspects by pharmacy personnel at LDF clinic in Maseru.

Keywords: Diabetes mellitus, Hypertension, Patient counselling, Medication knowledge, lifestyle modifications, Pharmacy personnel

(C) 2018 The Authors. Published by Innovare Academic Sciences Pvt Ltd. This is an open access article under the CC BY license (http://creativecommons.org/licenses/by/4.0/) DOI: http://dx.doi.org/10.22159/ijpps.2018v10i3.24291

\section{INTRODUCTION}

Non-communicable diseases (NCDs) contributed to the rise in mortality in the world. According to the World Health Organization (WHO) [1], 38 million people died annually of NCDs with cardiovascular diseases responsible for 17.5 million deaths, cancer 8.2 million, respiratory diseases 4 million, and diabetes 1.5 million deaths. The 2014 World Health Organization NCDs national profile of Lesotho reported that $12 \%$ of deaths were due to cardiovascular diseases, 3\% diabetes mellitus and 3\% due to respiratory diseases [2]. The World Health Organization [3] stated that $27 \%$ of deaths in Lesotho were due to NCDs.

Patient knowledge on diabetes mellitus management includes medicine use, risk factors associated with diabetes mellitus, and lifestyle modifications [4] which are important factors in pharmaceutical care of diabetic patients. Adequate patient knowledge on their diseases, complications associated with those diseases, and drug therapy can improve self-management which forms a vital part of an effective treatment plan [4] thus, improving patient compliance to treatment and decreasing complications associated with the disease [5]. Furthermore, patient knowledge of blood pressure (BP) in hypertension, blood glucose control in diabetes mellitus, and medications adherence play an important role in the management of diabetes mellitus and hypertension $[6,7]$.

Patient counselling is an effective method to improve patient medication adherence [7]. Counselling involves patient education on diseases and their complications, medication use and storage, and lifestyle modifications $[7,8]$. Pharmacy personnel have to encourage patient understanding on how the prescribed treatment works with emphasis on medicines dosing frequency, route of administration and side effects [6]. Benefits of patient counselling include improved patient understanding of their diseases and its treatment, adherence, and improved therapeutic outcome [6, 7]. Additionally, pharmacists are able to gain knowledge of medication use from the patient's perspective [7]. Educating patients about their disease states and medication can also increase their active participation in therapy and improve medication adherence [9].

Pharmacists are the third largest health profession in the world after doctors and nurses [10] and help to identify, assess, educate, refer and continuously monitor patients in diabetes mellitus and hypertension management. Pharmacists are in a unique position to play a vital role in helping patients to cope with their disease and make informed decisions regarding management and medication through patient education [4, 10]. Therefore, responsibilities of pharmacists involve long-term patient supervision, patient education activities, consideration of medication-related issues such as side effects, and optimisation of medicinal treatment and adherence [11].

The challenge to adequate patient counselling for hypertensive and diabetic patients is the increasing number of patients. Thus, the rationale was that hypertensive and diabetic patients counselling is essential to enable patients to care for themselves at home, handle medication-related problems, and to improve adherence so due to patient increase, insufficient time was dedicated to delivering patient counselling. Therefore, the objective of this study was to determine if hypertensive and/or diabetic patients were counselled on disease states, medication (names, strengths, dose frequency, side effects and storage), and lifestyle modifications by pharmacy personnel at LDF clinic in Maseru 


\section{MATERIALS AND METHODS}

\section{Study setting}

The study was conducted at LDF clinic in Maseru district in Lesotho.

\section{Study design}

This was a cross-sectional study where data on hypertensive and/or diabetic patients knowledge regarding medication, disease states and lifestyle modification were collected from the study population at a single point in time (from March to May 2017) at LDF clinic in Maseru district in Lesotho.

\section{Target population}

The target population consisted of all male and female adult outpatients $18 \mathrm{y}$ of age and above with either diabetes mellitus, hypertension, or with both hypertension and diabetes mellitus at LDF clinic.

\section{Sampling}

The preliminary number of diabetic and/or hypertensive patients at LDF clinic was 523 in 2017. The sample size was calculated at 95\% confidence interval, with $5 \%$ margin of error. The calculated sample size used as the study population was 222 patients with diabetes mellitus and/or hypertension. No sampling method was used. Inclusion criteria were as follows: all diabetic and/or hypertensive outpatients (males and females) above $18 \mathrm{y}$ of age at LDF clinic that have been on diabetes mellitus and hypertension treatment for more than a year. An exclusion criterion was hypertensive and/or diabetic patients who did not visit the LDF clinic during the days when the researchers were gathering data.

\section{Data collection}

A semi-structured questionnaire with both open and closed-ended questions was used as a data collection tool. An extensive literature review of similar studies was conducted during the development of the semi-structured questionnaire that assisted in coming up with unambiguous questions. Additionally, the following studies were used to formulate the semi-structured questionnaire: (a) Study of knowledge, attitude, and practice of general population of Guntur towards silent killer diseases: hypertension and diabetes by Bollu et al. [12], and (b) Influence of post-discharge counselling on health outcomes in diabetic and hypertensive patients by Adepu et al. [6].
The questionnaire was prepared in both English and Sesotho languages. Hypertensive and/or diabetic patients attending the clinic were provided with information about the study and informed consent forms using their home language (Sesotho). Patients who gave their informed consent participated in the study. The researchers then conveniently conducted face-to-face interviews using the semi-structured questionnaire and looked through medication booklets of diabetic and/or hypertensive patients who attended the clinic during the days the researchers were gathering data at the clinic. The researchers checked the patients' medication booklets to confirm their diabetic and hypertensive states, antidiabetic and anti-hypertensive medication, and to confirm that they met the inclusion criteria.

\section{Time period}

Data were collected from March to May 2017 using semi-structured questionnaires in a face-to-face interview. Data was collected on Tuesdays, Wednesdays and Thursdays every week between 08:00 and 16:00.

\section{Data analysis}

Data were analysed using Microsoft Excel 2010. Descriptive statistics (frequency, percentage, mean, and standard deviation) was used to demonstrate characteristics of the study population. The responses from participants regarding the complications of hypertension and diabetes mellitus, lifestyle modifications, and medicines (names, strengths and dosing frequency) were classified using knowledge scores. Participants were said to have "adequate" knowledge if they mentioned at least five correct answers; "inadequate "knowledge if they mentioned at most four correct answers and "no" knowledge (Don't know) if they did not know.

Furthermore, participants were said to have "adequate" knowledge if they responded with a percentage score of "75-100\%"; "inadequate" knowledge " $<75 \%$ but $>0 \%$ " and "no" knowledge (Don't know) if they did not know anything, with a percentage score of " $(0 \%)$ ".

\section{Ethical approval and consent to participate}

Ethical approval was granted by the Local Research Ethics Committee of the National University of Lesotho (NUL) and the Ministry of Health Research and Ethics Committee of Lesotho, registration number 76-2017. Goodwill permission to conduct the study was obtained from the LDF clinic manager. The study participants gave their informed consent.

\section{RESULTS}

Table 1: Age, gender and disease state(s) distribution of respondent

\begin{tabular}{lll}
\hline Age group (y) & Frequency (n) & Percentage (\%) \\
\hline $21-30$ & 16 & $7.2 \%$ \\
$31-40$ & 44 & $19.8 \%$ \\
$41-50$ & 63 & $28.4 \%$ \\
$51-60$ & 55 & $24.8 \%$ \\
$61-70$ & 35 & $15.8 \%$ \\
$71-80$ & 9 & $4.1 \%$ \\
Total respondents & $\mathbf{2 2 2}$ & $\mathbf{1 0 0 . 0 \%}$ \\
Gender & Frequency (n) & Percentage (\%) \\
Male & 46 & $20.7 \%$ \\
Female & 176 & $\mathbf{7 9 . 3 \%}$ \\
Total respondents & $\mathbf{2 2 2}$ & $\mathbf{1 0 0 . 0 \%}$ \\
Disease state(s) & Frequency (n) & Percentage (\%) \\
Hypertension & 144 & $64.9 \%$ \\
Diabetes mellitus & 29 & $\mathbf{1 3 . 1 \%}$ \\
Hypertension and diabetes mellitus & 49 & $22.1 \%$ \\
Total respondents & $\mathbf{2 2 2}$ & $\mathbf{1 0 0 . 0 \%}$ \\
\hline
\end{tabular}

Table 1 shows that the majority $(63,28.4 \%)$ of respondents were in the age group range $41-50$ and the majority $(176,79.3 \%)$ of respondents were female. Table 1 also indicates that about two thirds $(144,64.9 \%)$ of respondents had hypertension. 
Table 2: Distribution of respondents by highest level of education

\begin{tabular}{lll}
\hline Highest level of education & Frequency (n) & Percentage (\%) \\
\hline Primary school & 98 & $44.1 \%$ \\
Secondary school & 70 & $31.5 \%$ \\
High school & 29 & $13.1 \%$ \\
College & 16 & $7.2 \%$ \\
University & 7 & $3.2 \%$ \\
No education & 2 & $0.9 \%$ \\
Total respondents & 222 & $100.0 \%$ \\
\hline
\end{tabular}

According to table 2 , the majority $(98,44.1 \%)$ of respondents had primary school level of education.

Table 3: Age, fasting blood glucose (FBG) level and blood pressure (BP) means

\begin{tabular}{|c|c|c|c|c|c|c|}
\hline Variable & Mean ( $\pm s d)$ & & Minimum & & Maximum & \\
\hline Age (Years) & $48.7 \pm 12.0$ & & 21 & & 77 & \\
\hline Fasting Blood Glucose (mmol/l) & $6.9 \pm 2.0$ & & 3.9 & & 14.5 & \\
\hline Blood Pressure (mmHg) & Systolic BP & Diastolic BP & Systolic BP & Diastolic BP & Systolic BP & Diastolic BP \\
\hline SD: Standard deviation & $143.4 \pm 13.8$ & $89.6 \pm 8.2$ & 110 & 51 & 194 & 110 \\
\hline
\end{tabular}

Table 3 indicates that the mean age of respondents was $48.7 \pm 12.0 \mathrm{y}$, mean fasting blood glucose (FBG) level of diabetic respondents was $6.9 \pm 2.0$ $\mathrm{mmol} / \mathrm{l}$, mean systolic blood pressure (BP) of hypertensive patients was $143.4 \pm 13.8 \mathrm{mmHg}$, and the mean diastolic BP was $89.6 \pm 8.2 \mathrm{mmHg}$.

Table 4: Knowledge regarding hypertension and diabetes mellitus

\begin{tabular}{lll}
\hline Disease incurable & Frequency (n) & Percentage (\%) \\
\hline Yes & 177 & $79.7 \%$ \\
No & 0 & $0.0 \%$ \\
Don't know & 45 & $20.3 \%$ \\
Total respondents & 222 & $100.0 \%$ \\
Complications of diabetes mellitus & $\mathrm{N}=78$ & Percentage (\%) \\
Retinopathy & Frequency (n) & $11.5 \%$ \\
Diabetic foot & 9 & $23.1 \%$ \\
Nephropathy & 18 & $1.3 \%$ \\
Neuropathy & 1 & $0.0 \%$ \\
Complications of hypertension & 0 & $\mathrm{~N}=193$ \\
Stroke & Frequency (n) & 160 \\
Kidney failure & 8 & $82.9 \%$ \\
Heart attack & $6.1 \%$ \\
Heart failure & 6 & $3.1 \%$ \\
\hline
\end{tabular}

Table 4 shows that about two thirds $(177,79.7 \%)$ of respondents knew that the diseases were incurable. The majority (18, 23.1\%) of respondents knew about a diabetic foot as a complication of diabetes mellitus. Additionally, the majority (160, 82.9\%) of respondents knew that stroke was a complication for hypertension.

Table 5: Knowledge regarding target blood pressure (BP) and fasting blood sugar (FBG) level

\begin{tabular}{lll}
\hline Blood pressure (BP) & Frequency (n) & Percentage (\%) \\
\hline$<140 / 90 \mathrm{mmHg}$ & 97 & $50.3 \%$ \\
$\geq 140 / 90 \mathrm{mmHg}$ & 0 & $0.0 \%$ \\
Don't know & 96 & $49.7 \%$ \\
Total respondents & 193 & $100.0 \%$ \\
Fasting blood sugar (FBG) & Frequency (n) & Percentage (\%) \\
$<6.2 \mathrm{mmol} / \mathrm{l}$ & 28 & $35.9 \%$ \\
$\geq 6.2 \mathrm{mmol} / \mathrm{l}$ & 0 & $0.0 \%$ \\
Don't know & 50 & $64.1 \%$ \\
Total respondents & 78 & $100.0 \%$ \\
\hline
\end{tabular}

Table 5 indicates that half $(97,50.3 \%)$ of respondents knew the target BP, and more than half $(50,64.1 \%)$ of respondents did not know the target FBG level.

Table 6: Knowledge regarding lifestyle modifications of diabetes mellitus and hypertension

\begin{tabular}{|c|c|c|}
\hline \multirow[t]{2}{*}{ Lifestyle modifications in diabetes mellitus and hypertension } & \multicolumn{2}{|l|}{$\mathrm{N}=222$} \\
\hline & Frequency (n) & Percentage (\%) \\
\hline Weight loss if obese & 20 & $9.0 \%$ \\
\hline Reduce intake of fatty foods & 210 & $94.6 \%$ \\
\hline Reduce alcohol consumption & 48 & $21.6 \%$ \\
\hline Smoking cessation & 17 & $7.7 \%$ \\
\hline Restrict salt intake & 186 & $83.8 \%$ \\
\hline Physical exercise & 67 & $30.2 \%$ \\
\hline Keeping stress under control & 60 & $27.0 \%$ \\
\hline Intake of fruits and vegetables & 88 & $39.6 \%$ \\
\hline Reduce sugar intake & 37 & $16.7 \%$ \\
\hline
\end{tabular}

Table 6 shows that the majority $(186,83.8 \%)$ of respondents knew about salt intake restriction as one of the lifestyle modifications in diabetes mellitus and hypertension. 
Table 7: Knowledge regarding hypertension and diabetes mellitus medication names and strengths

\begin{tabular}{|c|c|c|}
\hline Hypertension medication names & Frequency (n) & Percentage (\%) \\
\hline Hydrochlorothiazide $(\mathrm{N}=192)$ & 168 & $87.5 \%$ \\
\hline Atenolol $(\mathrm{N}=109)$ & 86 & $78.9 \%$ \\
\hline Captopril (N=147) & 118 & $80.3 \%$ \\
\hline Hydralazine $(\mathrm{N}=2)$ & 1 & $50.0 \%$ \\
\hline Aspirin $(\mathrm{N}=103)$ & 89 & $86.4 \%$ \\
\hline Nifedipine $(\mathrm{N}=56)$ & 37 & $66.1 \%$ \\
\hline Diabetes mellitus medication names & Frequency (n) & Percentage (\%) \\
\hline Glibenclamide $(\mathrm{N}=29)$ & 22 & $75.9 \%$ \\
\hline Metformin $(\mathrm{N}=57)$ & 53 & $93.0 \%$ \\
\hline Insulin $(\mathrm{N}=49)$ & 46 & $95.8 \%$ \\
\hline Hypertension medication strengths & Frequency (n) & Percentage $(\%)$ \\
\hline Hydrochlorothiazide 25 mg (N=192) & 76 & $39.6 \%$ \\
\hline Atenolol $50 \mathrm{mg}$ and $100 \mathrm{mg}(\mathrm{N}=109)$ & 44 & $40.4 \%$ \\
\hline Captopril $25 \mathrm{mg}$ and $50 \mathrm{mg}(\mathrm{N}=147)$ & 56 & $38.1 \%$ \\
\hline Hydralazine $25 \mathrm{mg}(\mathrm{N}=2)$ & 0 & $0.0 \%$ \\
\hline Aspirin $150 \mathrm{mg}(\mathrm{N}=103)$ & 34 & $33.0 \%$ \\
\hline Nifedipine $10 \mathrm{mg}(\mathrm{N}=56)$ & 20 & $35.7 \%$ \\
\hline Diabetes mellitus medication strengths & Frequency (n) & Percentage (\%) \\
\hline Glibenclamide 5 mg $(\mathrm{N}=29)$ & 8 & $27.6 \%$ \\
\hline Metformin $500 \mathrm{mg}$ and $850 \mathrm{mg}(\mathrm{N}=57)$ & 22 & $38.6 \%$ \\
\hline Insulin $100 \mathrm{IU} / \mathrm{ml}(\mathrm{N}=49)$ & 1 & $2.1 \%$ \\
\hline
\end{tabular}

$\mathrm{N}=$ Total number of patients on that particular drug; $\mathrm{n}=$ patients who know the name of that particular drug.

Table 7 shows that the majority $(168,87.5 \%)$ of respondents on an anti-hypertensive drug, hydrochlorothiazide, knew its name, and the majority $(46,95.8 \%)$ of respondents on an anti-diabetic drug, insulin, knew its name. Table 7 also shows that the majority (44, $40.4 \%$ ) of respondents on an anti-hypertensive drug, atenolol, knew its strength, and the majority $(22,38.6 \%)$ of respondents on an antidiabetic drug, metformin, knew its strength.
Table 8 shows that the majority $(187,97.4 \%)$ of respondents on an anti-hypertensive drug, hydrochlorothiazide, knew its dosing frequency, and the majority $(49,100.0 \%)$ of respondents on an antidiabetic drug, insulin, knew its dosing frequency. Additionally, table 8 shows that the majority $(91,41.0 \%)$ of respondents store their diabetes mellitus and/or hypertension medicines at room temperature.

Table 8: Knowledge regarding hypertension and diabetes mellitus medication dosing frequency and storage

\begin{tabular}{|c|c|c|}
\hline Hypertension medication dosing frequency & Frequency (n) & Percentage (\%) \\
\hline Hydrochlorothiazide o. d. $(\mathrm{N}=192)$ & 187 & $97.4 \%$ \\
\hline Atenolol o. d. $(\mathrm{N}=109)$ & 100 & $91.7 \%$ \\
\hline Captopril b. d. and t. d. s. $(\mathrm{N}=147)$ & 127 & $86.4 \%$ \\
\hline Hydralazine o. d. $(\mathrm{N}=2)$ & 1 & $50.0 \%$ \\
\hline Aspirin o. d. $(\mathrm{N}=103)$ & 96 & $93.2 \%$ \\
\hline Nifedipine b. d. and t. d. s. $(\mathrm{N}=56)$ & 47 & $83.9 \%$ \\
\hline Diabetes mellitus medication dosing frequency & Frequency (n) & Percentage $(\%)$ \\
\hline Glibenclamide o. d. and b. d. $(\mathrm{N}=29)$ & 26 & $89.7 \%$ \\
\hline Metformin b. d. and t. d. s. $(\mathrm{N}=57)$ & 53 & $93.0 \%$ \\
\hline Insulin b. d. $(\mathrm{N}=49)$ & 49 & $100.0 \%$ \\
\hline Medication storage & Frequency (n) & Percentage $(\%)$ \\
\hline Room temperature ( 15 to $25^{\circ} \mathrm{C}$ ) & 91 & $41.0 \%$ \\
\hline Cool temperature $\left(8\right.$ to $\left.15^{\circ} \mathrm{C}\right)$ & 26 & $11.7 \%$ \\
\hline Refrigeration $\left(2\right.$ to $\left.8^{\circ} \mathrm{C}\right)$ & 18 & $8.1 \%$ \\
\hline Freezing temperatures $\left(-10\right.$ to $\left.-25^{\circ} \mathrm{C}\right)$ & 0 & $0.0 \%$ \\
\hline Warm temperatures $\left(>25^{\circ} \mathrm{C}\right)$ & 87 & $39.2 \%$ \\
\hline $\begin{array}{l}\text { Total respondents } \\
\text { o. d.-once daily, b. d.-twice daily, t. d. s.-three times daily }\end{array}$ & 222 & $100.0 \%$ \\
\hline
\end{tabular}

$\mathrm{N}=$ Total number of patients on that particular drug; $\mathrm{n}=$ patients who know the dosing frequency of that particular drug.

Table 9: Respondents who experienced diabetes mellitus and/or hypertension medicines side effects and action taken

\begin{tabular}{|c|c|c|}
\hline Medicine side-effects & Frequency (n) & Percentage (\%) \\
\hline Yes & 116 & $52.3 \%$ \\
\hline No & 106 & $47.7 \%$ \\
\hline Total respondents & 222 & $100.0 \%$ \\
\hline Side effects experienced & Frequency (n) & Percentage $(\%)$ \\
\hline Dizziness & 82 & $70.7 \%$ \\
\hline Headache & 19 & $16.4 \%$ \\
\hline Fatigue & 36 & $31.0 \%$ \\
\hline Redness at injection side & 5 & $4.3 \%$ \\
\hline Cough & 3 & $2.6 \%$ \\
\hline
\end{tabular}




\begin{tabular}{|c|c|c|}
\hline Medical action taken (if side-effects experienced) & Frequency (n) & Percentage (\%) \\
\hline Consult doctor immediately & 4 & $3.4 \%$ \\
\hline Consult doctor on the next visit & 8 & $6.9 \%$ \\
\hline No action taken & 102 & $87.9 \%$ \\
\hline Stop taking the medicine & 2 & $1.7 \%$ \\
\hline Total respondents & 116 & $100.0 \%$ \\
\hline Hypoglycaemia symptoms management & Frequency (n) & Percentage $(\%)$ \\
\hline Eat carbohydrates meal immediately & 4 & $5.1 \%$ \\
\hline Intake of sugar/sweets & 60 & $76.9 \%$ \\
\hline Eat carbohydrates meal immediately or intake of sugar/sweets & 9 & $11.5 \%$ \\
\hline Don't know & 5 & $6.4 \%$ \\
\hline Total respondents & 78 & $100.0 \%$ \\
\hline
\end{tabular}

Table 9 shows that the majority $(116,52.3 \%$ ) of respondents experienced diabetes mellitus and/or hypertension medicines side effects, 82 (70.7\%) of respondents experienced dizziness as a side effect, and $102(87.9 \%)$ of respondents who experienced medicines side effects did not take any medical action. Table 9 also shows that the majority $(60,76.9 \%)$ of respondents take sugar/sweets to manage hypoglycaemia symptoms.

Table 10: Knowledge scores regarding medication, disease states and lifestyle modifications

\begin{tabular}{|c|c|c|c|c|c|}
\hline Knowledge scores & $\begin{array}{l}\text { Frequency }(n) \text { and } \\
\text { percentage }(\%)\end{array}$ & $\begin{array}{l}\text { Adequate }(\geq \\
75 \%)\end{array}$ & $\begin{array}{l}\text { Inadequate }(<75 \% \\
\text { but }>0 \%)\end{array}$ & $\begin{array}{l}\text { Don't know } \\
(0 \%) \\
\end{array}$ & $\begin{array}{l}\text { Total } \\
\text { respondents }\end{array}$ \\
\hline Complications of diabetes & $\mathrm{n}$ & 0 & 22 & 56 & 78 \\
\hline mellitus & $\%$ & $0.0 \%$ & $28.2 \%$ & $71.8 \%$ & $100.0 \%$ \\
\hline Complications of & $\mathrm{n}$ & 8 & 152 & 33 & 193 \\
\hline hypertension & $\%$ & $4.1 \%$ & $78.8 \%$ & $17.1 \%$ & $100.0 \%$ \\
\hline \multirow[t]{2}{*}{ Lifestyle modifications } & $\mathrm{n}$ & 56 & 164 & 2 & 222 \\
\hline & $\%$ & $25.2 \%$ & $73.9 \%$ & $0.9 \%$ & $100.0 \%$ \\
\hline \multirow[t]{2}{*}{ Medication names } & $\mathrm{n}$ & 182 & 20 & 20 & 222 \\
\hline & $\%$ & $82.0 \%$ & $9.0 \%$ & $9.0 \%$ & $100.0 \%$ \\
\hline \multirow[t]{2}{*}{ Medication strengths } & $\mathrm{n}$ & 63 & 17 & 142 & 222 \\
\hline & $\%$ & $28.4 \%$ & $7.7 \%$ & $64.0 \%$ & $100.0 \%$ \\
\hline \multirow[t]{2}{*}{ Medication dosing frequency } & $\mathrm{n}$ & 199 & 20 & 3 & 222 \\
\hline & $\%$ & $89.6 \%$ & $9.0 \%$ & $1.4 \%$ & $100 \%$ \\
\hline
\end{tabular}

According to table 10 , more than half $(56,71.8 \%)$ of respondents did not know any diabetes mellitus complications, and more than half $(152$, $78.8 \%$ ) of respondents had inadequate knowledge of hypertension complications. About two thirds $(164,73.9 \%)$ of respondents had inadequate knowledge regarding lifestyle modifications in diabetes mellitus and hypertension. The majority $(183,82.0 \%)$ of respondents had adequate knowledge regarding their diabetes mellitus and/or hypertension medicines names, $142(64.0 \%)$ of respondents did not know any of their diabetes mellitus and/or hypertension medicines strengths, and 199 (89.6\%) of respondents had adequate knowledge regarding their diabetes mellitus and/or hypertension medicines dosing frequency.

\section{DISCUSSION}

Our study aimed to assess if diabetic and/or hypertensive patients were being adequately counselled by pharmacy personnel about their medications, disease states and lifestyle modifications at LDF clinic in Maseru. The aim was achieved through determination of knowledge of such aspects among diabetic and hypertensive patients visiting the clinic. In our study, the majority of respondents were hypertensive and the majority of respondents were female. Most respondents were within the age range of 41-50 y of age. The mean age of respondents was $48.7 \pm 12.0 \mathrm{y}$. additionally, most respondents had primary school educational level.

Our study showed that the mean systolic BP and the mean diastolic BP for hypertensive patients were high. Therefore, hypertensive patients had high uncontrolled BP despite the fact that they were on anti-hypertensive medicines. In a study conducted by Akoko et al. in Cameroon, BP control was poor, with less than half of the participants (42.1\%) having good BP [13] and these findings were consistent with the findings in our study. The normal systolic BP should be $<120 \mathrm{mmHg}$ and the normal diastolic BP should be $<80$ mmHg [14]. Also, our study showed that the mean FBG level was high for diabetic patients meaning glycaemic control was poor among diabetic patients even though they were taking anti-diabetic medicines. Our findings were consistent with those in a study by Dekker et al. which showed that inadequate glycaemic control was present in $74 \%$ of all diabetic patients [15]. Additionally, a study by Nepal et al. conducted in Nepal revealed that among 89 type 2 diabetic respondents only 27 (30.34\%) had normal FBG level [16]. The Global Diabetes Community [17] stated that normal FBG level should be within a range of 4-7 mmol/l for people with type 1 or type 2 diabetes mellitus. The uncontrolled BP and blood glucose levels, although the patients were on drug treatment, suggested that inadequate counselling on medicine use and lifestyle modification in controlling BP and the glycaemic level was not provided to patients by pharmacy personnel. A study conducted by Adepu et al. on postdischarge counselling in diabetic and hypertensive patients showed that there was improvement in BP and capillary blood glucose levels in test group patients compared to control group patients due to patient education on medication adherence behaviour, dietary changes adoption and lifestyle modifications [6].

In our study, half of the respondents knew the target BP and more than half of respondents did not know the target FBG level. Thus, pharmacy personnel at LDF clinic provided adequate patient counselling on target BP as opposed to target FBG level of which knowledge of target BP and FBG level is essential in self-monitoring of hypertension and diabetes mellitus, respectively. A study by Nepal et al. conducted in Nepal showed that $74.16 \%$ of patients were aware of the importance of regular checking of BP hence, knowledge of patients regarding regular self-monitoring of blood glucose level and BP is essential [16]. Patient knowledge and awareness of target BP and FBG levels play important roles in the ability to successfully self-monitor hypertension and diabetes mellitus.

Our study also revealed that about two-thirds of respondents knew that hypertension and diabetes mellitus were incurable. The findings of our study were consistent with those in a study by Almas et al. where $166(76 \%)$ men and $162(73.3 \%)$ women agreed that hypertension was a lifelong disease (p-value 0.3) [18]. Respondents in our study knew that hypertension and diabetes mellitus were incurable thus patient counselling provided by pharmacy personnel at LDF clinic was adequate with regards to hypertension and diabetes mellitus being curable or incurable. The findings in our 
study were in contrast with those in a study by Familoni et al. indicating that one-third $(35.4 \%)$ of the patients knew that hypertension should be treated for life [19]. The findings in a study by Fairchild et al. were also in contrast with our findings where about two-thirds $(39,65 \%)$ of participants believed that their diabetes could be cured [20].

Hypertensive and diabetic patients develop complications due to poor awareness regarding the diseases and inadequate BP and blood glucose level control. In our study, the majority of respondents knew about a diabetic foot as a complication of diabetes mellitus and stroke as a complication of hypertension. A study by Obirikorang $e t$ al. conducted in Ghana showed that type 2 diabetes mellitus complication commonly known by diabetic patients was a diabetic foot $(51.5 \%)$ [21], which was consistent with our study findings. Knowledge scores in our study showed that the majority of respondents did not know about diabetes mellitus complications and the majority had inadequate knowledge about hypertension complications. Our study findings were consistent with a study by Obirikorang et al. conducted in Ghana indicating that a higher proportion of type 2 diabetes patients did not have adequate knowledge on diabetic complications [21]. A study by Adepu et al. showed that at baseline the majority of participants were unaware of asymptomatic hypertension and complications associated with it [22]. Additionally, our study findings were consistent with a study by Abd El-Hay et al. where most patients (67.3\%) had fair level of knowledge regarding symptoms and complications of hypertension [23]. Hypertensive and diabetic patients in our study were not aware of other complications of hypertension (kidney failure, heart attack, heart failure) and diabetes mellitus (retinopathy, nephropathy, neuropathy) suggesting that patients were not well informed about the complications of hypertension and diabetes mellitus during patient counselling by pharmacy personnel at the LDF clinic.

Our study also showed that most hypertensive and diabetic patients knew about salt intake restriction as one of the lifestyle modifications. A study by Abd El-Hay et al. on knowledge and perception related to hypertension and lifestyle behaviour modifications showed that the majority of patients knew about excessive salt intake increase (82.2\%) as a risk for developing hypertension [23]; their findings were consistent with the findings in our study. The findings in a study by Bollampally et al. showed that $66 \%$ of participants thought that taking less salt will control the BP; their findings were similar to the findings in our study [24].

Additionally, knowledge scores in our study revealed that majority of hypertensive and diabetic patients had inadequate knowledge of lifestyle modifications. Our study findings were in contrast with findings in a study by Abd El-Hay et al. where most patients (67.3\%) had a fair level of knowledge regarding lifestyle modifications to control hypertension [23]. In our study, hypertensive and diabetic patients had inadequate knowledge of lifestyle modifications (such as weight loss, fatty foods, alcohol and sugar intake reduction, physical exercise, stress management, and fruits and vegetables intake) in hypertension and diabetes mellitus management due to poor patient counselling on lifestyle modifications by pharmacy personnel at LDF clinic.

Patient counselling includes providing verbal and/or written medication information on directions of use, advice on side effects, and storage to patients. Our study revealed that hypertensive patients mostly knew hydrochlorothiazide by name and its dosing frequency while diabetic patients mostly knew insulin by name and its dosing frequency. The findings in our study also showed that the majority of hypertensive patients on atenolol knew its strength and the majority of diabetic patients on metformin knew its strength. Knowledge scores on anti-hypertensive and anti-diabetic medicines in our study showed that most respondents had adequate knowledge of their medicine names and dosing frequencies, and about two-thirds of respondents did not know their medicines strengths. Our findings were consistent with a study by Bollampally et al. indicating that patients had good knowledge of prescribed drug names [24]. A study by Nnaemeka et al. revealed that most diabetic patients $(39,54.2 \%)$ knew the names of their anti-diabetic medications and the majority $(52,72.2 \%)$ of participants knew the dosing frequency of their anti-diabetic medicines [8]; their findings were similar to finding in our study. Adequate knowledge of medicine names and dosing frequencies as revealed by our study findings suggested that good counselling was provided by pharmacy personnel at LDF clinic on such aspects. On the other hand, there was poor knowledge regarding anti-hypertensive and anti-diabetic medicines strengths suggesting lack of patient counselling regarding medicines strengths.

The majority of respondents in our study experienced antihypertensive and anti-diabetic medicines side effects and the side effect mostly experienced by respondents was dizziness which could be due to uncontrolled levels of BP and FBG. Our findings were in contrast with those in a study by Manobharathi et al. where 90 $(83.3 \%)$ diabetic patients on anti-diabetic medicines had no side effects with the medicine [25]. One of the factors affecting uncontrolled levels of BP and FBG in hypertensive and diabetic patients, respectively include non-compliance to medicines due to side effects. A study by Manobharathi et al. showed that experiencing side effects and reporting the side effects experienced were found to be more among non-compliant patients compared to compliant patients [25]. A study by Akoko et al. also revealed that participants who reported side effects of their drugs were significantly less compliant than those who had never experienced any side effects [13]. Additionally, our findings showed that most hypertensive and diabetic patients who experienced medicines side effects did not take any medical action. Our study findings suggested the serious need for pharmacy personnel to improve patient counselling on medication side effects as well as actions patients should take when experiencing these side effects. Also, most respondents in our study took sugar/sweets to manage hypoglycaemic symptoms thus hypertensive and diabetic patients knew how to manage hypoglycaemia. Our findings were comparable with findings from a study by Adepu et al. indicating that most of the patients were aware of how to recognise and control the hypoglycaemic symptoms [22]. Therefore, there was adequate counselling regarding the management of hypoglycaemic symptoms by pharmacy personnel at LDF clinic.

\section{Limitations}

Some of the respondents were not eager to participate in the study because they thought their participation would affect the type of clinical services they were offered at the LDF clinic.

\section{CONCLUSION}

There is an increasing burden of non-communicable diseases such as diabetes mellitus and hypertension in the world which requires patients to take medicines. Therefore, the interaction between diabetic and/or hypertensive patients and pharmacy personnel through patient counselling has an impact on adherence to therapy. Poor relationship between patients and pharmacy personnel results in poor adherence to medication which is associated with higher glucose levels for the diabetic patient and high blood pressure for hypertensive patients. In general, there is inadequate patient knowledge regarding diabetes mellitus and hypertension complications, target blood pressure and fasting blood glucose levels, lifestyle modifications, medicines strengths, and medical actions to take when experiencing side effects in diabetes mellitus and hypertension management due to poor patient counselling by pharmacy personnel at LDF clinic in Maseru, Lesotho. Our study has therefore revealed that hypertensive and diabetic patients lack valuable information about their medicines, disease states and lifestyle modification thus counselling strategies to strengthen patient counselling should be developed.

\section{AUTHORS CONTRIBUTIONS}

Lineo Maja developed the study, collected and analysed the data, and wrote the first draft of the paper. Additionally, Lineo Maja read and approved the final manuscript.

Thabiso Masia developed the study, collected and analysed the data, and wrote the first draft of the paper.

Kabelo Binyane developed the study, collected and analysed the data, and wrote the first draft of the paper. 
Maseabata Ramathebane read and approved the final manuscript.

\section{CONFLICTS INTERESTS}

All authors declare that they have no conflict of interest

\section{REFERENCES}

1. World Health Organization. Non-communicable diseases fact sheet; 2015. http://www.who.int/mediacentre/factsheets/fs355/en/. [Last accessed on 11 Apr 2016].

2. World Health Organization. Non-communicable diseases (NCDs) country profile; 2014. http://www.who.int/nmh/ countries/lso_en.pdf. [Last accessed on 28 Feb 2017]

3. World Health Organization. Non-communicable diseases progress monitor; 2015. http://apps.who.int/iris/bitstream/ 10665/184688/1/9789241509459_eng.pdf. [Last accessed on 28 Feb 2017].

4. Renuga E, Ramakrishnan SR, Vanitha RN, Thennarasu P, Kannan G. Impact of continuous patient counselling on knowledge, attitude, and practices and medication adherence of diabetic patients attending outpatient pharmacy services. Asian J Pharm Clin Res 2016;9:364-9.

5. Obirikorang Y, Obirikorang C, Anto EO, Acheampong E, Batu $\mathrm{EN}$, Stella AD, et al. Knowledge of complications of diabetes mellitus among patients visiting the diabetes clinic at Sampa Government Hospital, Ghana: a descriptive study. BMC Public Health 2016;16:637.

6. Adepu R, Madhu S. Influence of post-discharge counselling on health outcomes in diabetic and hypertensive patients. Asian J Pharm Clin Res 2011;4:28-33.

7. Naveen B, Mahaboojan M, Padmanabha YR, Narayana G. Impact of clinical pharmacist mediated patient counselling on healthrelated quality of life in hypertensive patients. Indian J Pharm Pract 2014;7:34-40.

8. Nnaemeka OR, Kingsley NC. Evaluation of patient's antidiabetic medication counselling provided in a tertiary health care setting Nigeria. Int Res J Pharm 2012;3:319-23.

9. Inamdar SZ, Kulkarni RV, Karajgi SR, Manvi FV, Ganachari MS, Mahendra Kumar BJ. Medication adherence in diabetes mellitus: an overview on pharmacist role. Am J Adv Drug Delivery 2013;1:238-50.

10. Hughes JD, Wibowo Y, Sunderland B, Hoti K. The role of the pharmacist in the management of type 2 diabetes: current insights and future directions. Int Pharm Res Pract J 2017;6:15-27.

11. Antoine SL, Pieper D, Mathes T, Eikermann M. Improving the adherence of type 2 diabetes mellitus patients with pharmacy care: a systematic review of the randomized rolled trial. BMC Endocr Disord 2014;14:53.

12. Bollu M, Nalluri KK, Prakash AS, Lohith MN, Venkataramarao N. Study of knowledge, attitude, and practice of general population of Guntur toward silent killer diseases: hypertension and diabetes. Asian J Pharm Clin Res 2015;8:74-8.
13. Akoko MB, Fon NP, Ngu CR, Ngu BK. Knowledge of hypertension and compliance with therapy among hypertensive patients in the Bamenda health district of Cameroon: a cross-sectional study. Cardiol Ther 2017;6:53-67.

14. American Heart Association. Understanding blood pressure readings; 2016. http://www.heart.org/HEARTORG/Conditions/ HighBloodPressure/KnowYourNumbers/Understanding-BloodPressure-Readings_UCM_301764_Article.jsp\#.Wdtj6I-CzIU. [Last accessed on 09 Oct 2017]

15. Dekker MA, Amick EA, Scholcoff C, Doobay-Persaud A. A mixedmethods needs assessment of adult diabetes mellitus (type II) and hypertension care in Toledo, Belize. BMC Health Serv Res 2017;17:171.

16. Nepal C, Vyas P, Bhattarai R, Acharya B, Thapa K, Shrestha SJ, et al. Knowledge, attitude and practice of type 2 diabetic patients of selected outreach clinic, Dharan, Nepal. Al Ameen J Med Sci 2017;10:78-85.

17. The Global Diabetes Community. Blood sugar level ranges; 2017. http://www.diabetes.co.uk/diabetes_care/blood-sugarlevel-ranges.html. [Last accessed on 09 Oct 2017]

18. Almas A, Godil SS, Lalani S, Samani AZ, Khan HA. Good knowledge about hypertension is linked to better control of hypertension; a multicentre cross-sectional study in Karachi, Pakistan. BMC Res Notes 2012;5:579.

19. Familoni OB, Ogun AS, Aina OA. Knowledge and awareness of hypertension among patients with systemic hypertension. J Natl Med Assoc 2004;96:620-4.

20. Fairchild CP, Nathan GA, Quinn M, Huang SE, Laiteerapong N. Patients' future expectations for diabetes and hypertension treatments: "through the Diet... I think this is going to go away. J Gen Intern Med 2016;32:49-55.

21. Obirikorang Y, Obirikorang C, Anto OE, Acheampong E, Batu NE, Stella DA, et al. Knowledge of complications of diabetes mellitus among patients visiting the diabetes clinic at Sampa Government Hospital, Ghana: a descriptive study. BMC Public Health 2016;16:637.

22. Adepu R, Somashekar MA. Influence of structured patient education on therapeutic outcomes in diabetes and hypertensive patients. Asian J Pharm Clin Res 2010;3:174-8.

23. Abd El-Hay AS, El Mezayen ES. Knowledge and perceptions related to hypertension, lifestyle behaviour modifications and challenges that facing hypertensive patients. J Nurs Health Sci 2015;4:15-26.

24. Bollampally $M$, Chandershekhar P, Kumar KP, Surakasula A, Srikanth S, Reddy TRM. Assessment of patient's knowledge, attitude and practice regarding hypertension. Int J Res Med Sci 2016;4:3299-304.

25. Manobharathi M, Kalyani P, John William Felix A, Arulmani A. Factors associated with therapeutic non-compliance among type 2 diabetes mellitus patients in Chidambaram, Tamilnadu, India. Int J Community Med Public Health 2017;4:787-91. 